\title{
DE CASA À ESCOLA: O DESENHO DO CAMINHO PERCORRIDO NUMA ABORDAGEM HUMANISTA
}

\author{
Aderbal Pereira Santana Filho ${ }^{1}$ \\ Lílian Miranda Bastos Pacheco ${ }^{2}$
}

\begin{abstract}
Resumo: É sempre bom pensar o lugar em que vivemos, estabelecer elos e construir espaços de vivência em que o humano, esteja no centro, não na visão antropocêntrica, mas no estabelecimento das relações em que o ouvir e falar, sejam expressões marcantes e definitivas. Esta Geografia Humanista é mais uma forma, distinta de tantas outras, de fazer geografia. Esta análise apresenta os mapas mentais, como ferramenta da aprendizagem do desenho cartográfico, caracterizando o risco e rabisco dos alunos do 10 ano do Ensino Médio, de uma escola particular, da cidade de Ilhéus, na Bahia, expressando assim a percepção que estes mesmos alunos possuem do percurso realizado da casa à escola, a partir da confecção do mapa mental em folha de oficio, com objetivo de desenvolver a percepção do lugar. 0 resultado encontra-se centrado no registro da percepção e representação que o aluno possui, através do mapa mental construído por ele, associado a uma tomada de consciência do lugar em que vive.
\end{abstract}

Palavras-Chave: Geografias, Geografia humanista, Mapa mental.

Resumen: Es siempre bueno pensar en el lugar donde vivimos, establecer vínculos y construir espacios de vivencia donde el humano esté en el centro, no en una visión antropocéntrica, pero en el establecimiento de las relaciones en que el oír y hablar sean expresiones marcadas y definitivas. Esta Geografía Humanista es más una forma, distinta de tantas otras, del hacer geografía. Este análisis presenta los mapas mentales, como herramienta del aprendizaje del diseño cartográfico, caracterizando el trazo y escarabajeo de los alumnos del primer año de la enseñanza media, de una escuela privada, de la ciudad de Ilhéus, en Bahía, expresando de esa manera la percepción que los mismos poseen del trayecto realizado desde casa hasta la escuela, a partir de la confección del mapa mental en hoja de papel, con el propósito de desarrollar la percepción del lugar. El resultado se encuentra centrado en el registro de la percepción y representación que el alumno posee, a través del

1 Professor do Ensino Básico, Secretaria Educação da Bahia; mestrado em andamento: Desenho, Cultura e Interatividade; Orientadora: Lilian Miranda Bastos Pacheco, Universidade Estadual de Feira de Santana (UEFS); especialista em Ensino de Geografia, Faculdade do Noroeste de Minas (FINOM); licenciado em Geografia, Universidade Estadual de Santana Cruz (UESC); Grupo de Pesquisa: Desenvolvimento Humano e Processos Educativos/UEFS. Endereço eletrônico: aderbal_geografo@hotmail.com.

2 Docente do Programa de Pós-Graduação em Desenho, Cultura e Interatividade (PPGDCI/UEFS); Grupo de Pesquisa: Desenvolvimento Humano e Processos Educativos. Endereço eletrônico: dlp.ba@terra.com.br. 
mapa mental construido por él, asociado a un cobrar de consciencia del lugar donde se vive.

Palabras-Llave: Geografías, Geografía humanista, Mapa mental.

\section{INTRODUÇÃO}

Nas últimas décadas do século $X X$, as concepções acerca do ambiente vivido e percebido, estiveram nas principais pautas dos congressos, promovendo debates e discussões, quer seja por causa da necessidade de responder à crise que assola a humanidade, referente à desumanização ou do modelo capitalista e de consumo de massa, os quais não estão interessados em resolver as questões sociais e humanitárias, exceto quando é conveniente ao capital.

Esta humanidade habita um mundo repleto de imagens e representações e possui olhos (órgão dos sentidos) que se abrem como janelas. Contudo, ainda acreditando enxergar, não consegue ver em sua plenitude, uma vez que perceber vai além da visão e da sensação.

Verifica-se também que no ambiente escolar, quando o assunto versa sobre concepção do espaço geográfico, os alunos demonstram certa limitação em perceber os detalhes, principalmente em se tratando das questões relacionadas ao estudo dos mapas e o que eles representam. Eles, descendentes da Era da Tecnologia, sempre conectados em rede, o "tempo" parece que é extremamente volátil, encontram-se limitados quanto ao perceber, aprofundar e mensurar. Por conta deste "tempo", seus olhos enxergam, mas não conseguem "ver".

Esta fluidez e ao mesmo tempo a quantidade de informação que é despejada no cotidiano dos alunos, parece não oportunizá-los aprofundar as temáticas, principalmente quando a referência é a humanidade e temas ligados à cartografia.

Portanto, a iniciativa em escrever este artigo surgiu após desenvolver uma atividade cartográfica, na qual cada aluno representou o percurso realizado por ele da sua casa à escola e, ter assistido como atividade de finalização da disciplina Epistemologia da Geografia, a entrevista da professora e doutora Rita Jaqueline Nogueira Chiapetti, a respeito dos desafios encontrados no percurso da construção de sua Tese de Doutorado: "na beleza do lugar, o Rio das Contas indo... ao mar".

Desta forma, o objetivo aqui apresentado é entender como o aluno percebe o espaço que se encontra em seu entorno, a partir da construção 
do desenho do mapa mental, levando em consideração a experiência e vivência dele.

Durante a segunda semana de aula foi realizado uma atividade a partir da percepção que os mesmos tinham a respeito do percurso realizado das suas casas até à escola. Trata-se de uma escola particular, da cidade de Ilhéus-Bahia e turmas do 10 ano do Ensino Médio. Seguiram-se os seguintes passos: a) ainda na sala de aula, o professor apresentou a temática denominada de "conhecendo o espaço geográfico"; b) em seguida, o professor conduziu os alunos, até uma área próxima à piscina, a qual está voltada para o oceano e ali foram apresentados os conceitos de paisagem natural e modificada; c) retornando à sala de aula, foi entregue a cada aluno uma folha de ofício e o professor solicitou que o mesmo desenhasse o percurso que ele fazia da sua casa até a escola, colocando símbolos percebidos neste caminho; d) os mapas foram agrupados em quatro blocos distintos, cada um representando uma turma: $A, B, C$ ou $D$; em seguida, foi feito um leque de cada bloco com os desenhos virados para baixo e por fim, retirou-se um de cada turma, que passou a compor este artigo.

\section{PERCORRENDO AS FORMAS DE FAZER GEOGRAFIA}

A geografia ao longo de sua história vem passando por diversas transformações e no final do século XX e inicio deste, o debate em torno das concepções cultural e humanista tornaram-se temas centrais de discussão nos congressos e seminários. Por isso há uma reflexão sobre esta questão paradigmática de fazer ciência, em relação ao século passado, à luz do que pensam Camargo e Guerra (2007, p. 128), quando eles afirmam que "justificou seu progresso nas bases científicas [...] funcionando como verdade absoluta e praticamente inquestionável." Nas falas desses autores, é possível compreender que existia uma forma de se fazer ciência, a qual não tinha como fator imediato a experiência do vivido pelo homem, suas relações com o espaço e muito menos as suas inquietações e angústias vividas por ele. Daí ser essencial a retomada das concepções de ver e viver o espaço habitado por ele.

Desta forma, é necessário que as pessoas percebam o que existe em seu entorno, buscando entender os signos e códigos que os representam, a fim de melhor compreender o espaço em que vivem, centrando o pensar em ações capazes de minimizar os modelos de exploração impostos ao homem, pois como afirma Oliveira $(2002$, p. 191) "a percepção está subordi- 
nada às condições limitativas de proximidade no espaço e no tempo." Assim, a partir desta consciência, ocorre a transformação.

Em particular, a escola, a casa, o percurso entre estas, o bairro, todos estão incluídos neste universo, denominado de espaço da vivência. Este ambiente está repleto de simbolismo e necessita de uma leitura específica para compreendê-lo. O mapa pode tornar-se um instrumento eficaz, pois ele sempre esteve presente na vida do homem e este o utiliza até hoje, como elemento necessário à sua existência. Porém, quando se trata de desenhá-lo e interpretá-lo enquanto imagem surge inúmeras limitações, pois como afirma Paiva $(2006$, p. 17) a respeito dos registros "é preciso saber indagá-los e deles escutar as respostas."

Estas concepções ficaram evidenciadas durante o pronunciamento da professora Rita Jaqueline Nogueira Chiapetti, quando falou a respeito do "fazer geográfico" a partir da percepção, e iniciou sua fala dizendo que iria falar também com o coração. No decorrer, pontuou sobre as angústias de fazer uma pesquisa na concepção da Geografia Humanista, principalmente por causa da incompreensão que recai sobre esta. Finalizou sua reflexão afirmando que a percepção na Geografia encontra-se em tomar consciência do que é o mundo, como o vemos, de que forma agimos nele e qual a postura frente aquilo que vivemos.

Ao longo da historia, a Geografia vem utilizando o "olhar da paisagem" no intuito de entender o que acontece e quais os processos que conduzem às transformações do espaço. Este, que é modificado desde o momento em que o homem lança mão de técnicas e tecnologias, capazes de contribuir, levando-o a adequar a natureza às suas necessidades.

Ao referir-se às civilizações de regadio (aquelas que nasceram às margens dos rios) da antiguidade, como é o caso dos mesopotâmios e egípcios, buscava-se entender os processos associados ao nível da água, crescente fértil, irrigação, levando-os a melhor apropriação do espaço. Os gregos, durante a Antiguidade Clássica, estiveram voltados para o cosmo e as tentativas de explicar a Terra e seu formato, o que é visivelmente percebido nos desenhos construídos nesta época. Contudo, o fazer geográfico possuía um objetivo claro de descrição, como afirma Costa e Rocha (2010, p. 27) "os estudos geográficos tinham na maioria das vezes caráter descritivo e informativo."

Durante a Idade Média, em função do poder dogmático exercida pela Igreja, caracteriza-se por um período de estagnação e retrocesso do conhecimento até então produzido pela Geografia, muito voltada para entender o

94 Número temático: Desenho e Educação: Cultura Visual e Cidade. A Cor das Letras - UEFS, n. 
universo e responder as inquietantes dúvidas a respeito do lugar ocupado pela Terra no universo, bem como seus movimentos e como afirma CarvaIho (2001, p. 101) " entre os séculos II e o VI da era cristã a representação do mapa mundi desapareceu [...] obedeceram a descrição do Genesis da divisão do mundo."

Não obstante, neste período, destaca-se também a contribuição realizada pelos árabes, citado por Costa e Rocha (2010), seus interesses expansionistas, geraram a necessidade de conhecer os espaços a serem conquistados, agregando, à Geografia, novos relatos de espaços e rotas desconhecidos até então.

O mercantilismo atrelado às grandes navegações suscita uma nova abordagem neste fazer geográfico, pois para ir além mar é necessário o projeto cartesiano e com isso surge a especialização em técnica cartográfica. O desenho passa a ser uma ferramenta importantíssima para a Geografia e por que não dizer para toda a produção e dominação de uma época.

Trinchão e Oliveira (1998) apresentam o desenho que conta a história das civilizações e ao mesmo tempo, é a história das civilizações que podem ser contadas a partir do desenho. Aqui está bem claro o papel desempenhado por estes cartógrafos que constituíram uma maneira de fazer Geografia, intuindo e descrevendo espacialidades a serem dominadas, principalmente neste início da expansão marítima.

O confronto estabelecido entre as duas correntes do Pensamento Geográfico: Determinismo e Possibilismo, nos meados do século XIX, nos rendeu um novo fazer geográfico, pois enquanto Ratzel pensava o "espaço vital," La Blache constituía o "gênero de vida". Ambos motivados pelas exigências do seu tempo, ou seja, a partir do advento do capitalismo, necessitando de novas respostas às configurações que aos poucos iam sendo constituídas.

Se por um lado em Ratzel, conforme afirmam Costa e Rocha (2010, p. 32) o homem "é visto como uma espécie animal que busca se adaptar e controlar o meio natural", em La Blache, já é percebido como capaz de intervir na natureza, inclusive utilizando técnicas possíveis de adaptá-lo aos novos espaços construídos por ele. Ambos não estão preocupados em ouvir o que este homem sente, quais são as suas aspirações e como reage diante das coisas do mundo.

Após a II Guerra Mundial e a necessidade do Capitalismo tornar-se hegemônico frente ao Socialismo, os números tornaram-se ainda mais importantes, pois quantificar é algo precioso no modelo em que o lucro se faz 
presente e necessário. Assim nasce uma Geografia Nova, denominada de teorética/quantitativa. Esta nova forma de fazer geografia, esta centrada na matematização e, portanto encontra-se embasada, conforme afirmam Costa e Rocha (2010, p. 35), no "positivismo lógico ou neopositivismo."

Contrapondo o modelo capitalista, afloram ideias centradas nos princípios marxistas e mais uma vez a Geografia procurou dar conta das exigências que esta temporalidade exigia. Surge, a partir da década de 70, um novo fazer geográfico, denominado de Geografia Crítica, preconizada por Milton Santos, que ao retornar do exílio, transforma-se em um estandarte e levará não só para os meios acadêmicos do Brasil esta discussão, bem como para outros países.

Segundo Santos (2004, p. 225) "cada lugar é teatro de combinações pouco duráveis, cujo fator de mudança é esse dado global" e, portanto tudo parece volátil, efêmero, descartável incentivado pela Tecnologia de Informação e Comunicação (TIC), não valorando as ações do homem e a percepção que o mesmo tem de si e do mundo. Este tempo, descarta até o próprio homem.

O tempo pós moderno apresenta-se acentuando o discurso em prol do efêmero, pois do ferro de passar que trocava a resistência e continuava literalmente "ferro", hoje é um conjunto de elementos pouco resistentes e que o produto como um todo, tem curta vida útil, necessitando ser trocado, fenômeno que alimenta uma cadeia produtiva e de consumo.

Este exemplo, simplista, nos leva a pensar sobre quem é o homem neste novo tempo, pois surge uma nova concepção, voltada para entender o que ele pensa e como reage diante das coisas. Não é mais possível compreender o todo, pois este está por demais fragmentado e as informações numa dinâmica enorme, que não dá tempo de absorvê-las em sua totalidade.

No final do século passado e início deste, novos desafios são apresentados e agora a Geografia precisa pensar esta temporalidade, colocando o homem como sujeito e objeto ao mesmo tempo, pois como afirma Claval (2002, p. 26), "o geógrafo é uma testemunha do mundo. [...] Não hesitam mais em falar dos indivíduos, em contar a vida deles".

É desta forma de fazer Geografia que o tempo presente clama. Não que as outras não sirvam mais, porém as ameaças sofridas pelo planeta, o risco do desaparecimento das espécies, a regionalização do mundo em nome da globalização, ampliando a exclusão. Tudo isso, exige nova concepção, novo olhar a partir da percepção das contradições do vivido.

96 Número temático: Desenho e Educação: Cultura Visual e Cidade. A Cor das Letras - UEFS, n. 
O fazer geografia, portanto, baseado numa concepção humanista, considera o homem enquanto sujeito, que, percebendo o mundo em seu entorno, consciente de que está inserido nele, pode também se tornar objeto de estudo, relatando a percepção que possui das realidades que se encontram à sua frente.

\section{CONSTRUINDO O DESENHO DO MAPA MENTAL}

Durante muito tempo como todas as ciências, a Geografia também esteve centrada, lendo apenas a cartilha positivista cartesiana e por isso, o desenho do mapa era realizado milimetricamente, objetivando o máximo de precisão possível. Esta técnica não priorizava a construção cartográfica a partir da vivência das pessoas e sim na descrição espacial dos lugares.

$\mathrm{Na}$ verdade existe um mundo concebido e outro percebido e nem sempre as pessoas percebem este em que habitam, pois está tudo tão acelerado que não há tempo para olhar o "tempo que passa." Há uma complexidade associada a esta temporalidade, que embaraça-nos na hora de classificar o percebido, pois ele se encontra tão fragmentado, que precisa de muito tempo para compreendê-lo.

Portanto realizar a produção do mapa mental é antes de tudo levar o indivíduo a pensar o mundo em seu entorno pensando "a educação do desenho, que deveria ser, tal como a entendemos, de fundamental importância para a compreensão de aspecto da cultura material" (GOMES, 1996, p. 15). O autor procura enfatizar a importância do desenho, explicitando o quão se fez necessário, não só no exercício escolar de aprendizagem, mas principalmente no cunho cultural, fatores que corroboram para a compreensão e entendimento de outros povos, aprendendo desta forma a conviver com a diferença, respeitando-as nas suas particularidades.

A cartografia parte do olhar percebido e através deste órgão do sentido é possível registrar e captar a imagem, podendo ser rabiscada em um papel, representando de forma material, o imaterial percebido. Sobre esta forma de ver Santos (2011, p. 241), declara que "os mapas mentais trabaIhados foram analisados de forma a mostrarem o lugar visto por meio do olhar dos próprios moradores." Estes são autores da sua própria história.

Daí a necessidade de aproximar o indivíduo das construções cartográficas. Como afirma Ferreira (2005), a preocupação não se encontra na produção ou representação do desenho e sim na percepção de sua existência e na análise que dele se pode fazer. Comungando com essa ideia, Oliveira (1978) afirma que não é só desenhar o mapa, mas também saber o que ele 
representa, pois conseguindo entendê-lo, compreenderemos melhor a nossa história.

Os autores dialogam partindo da premissa que é importante a utilização da percepção, não podendo ser negligenciadas as várias interpretações que o mesmo pode apresentar, buscando entender o que está sendo representado, bem como o processo que levou ao produto final.

Ainda neste contexto, não podemos deixar de mencionar os signos e códigos que se transformam em elementos de extrema importância na leitura e interpretação cartográfica. Assim há de citar a importância da Semiótica, que, como afirma Rocha (2002/2003, p. 72) "é área do conhecimento que se dedica ao estudo dos signos, ou seja, de tudo aquilo que é produzido e pode ser interpretado." Por isso, "os elementos selecionados para um mapa mental pode tomar forma e tamanho, segundo a importância simbólica e material que eles representem para o indivíduo" (DE PAULA, 2010, p. 4).

O mundo e a vida não são cartesianos. Os sonhos e desejos não são constituídos de forma sequencial, geométrica e não há alinhamento perfeito quando se trata de emoção. A percepção do lugar passa a ser elemento crucial para a Geografia Humanista, possibilitando transformar o imaginário vivido pelos alunos em esboço, o qual representará a sua vida cotidiana, por vezes muito feliz ou emburrada e triste, quando traçam o percurso que realizam, concretamente, entre suas casas e a escola.

\section{ANÁLISE E DISCUSSÃO DOS MAPAS MENTAIS}

Os mapas mentais, aqui representados pelo desenho do percurso da casa do aluno até a escola, tornam-se uma excelente ferramenta que expressa o que é significativo para ele a ponto de ser retratado na representação que faz do espaço vivido, constituindo um tipo de linguagem. Esta atividade permite a personificação do lugar, visto que cada um constrói o mapa mediante as percepções que consegue abstrair a partir das observações, somadas às concepções constituídas pessoalmente ao longo de sua história de vida.

Em se tratando do estudo dos mapas, existem diversas tipos, sendo consenso entre autores como Moreira (1997), Souza e Boruchovitck (2010) e Ausubel (1980) que os do tipo mapas conceituais são diagramas que indicam as relações entre conceitos ou entre palavras que representam os referidos conceitos.

Número temático: Desenho e Educação: Cultura Visual e Cidade. A Cor das Letras - UEFS, $n$. 
Já em relação ao mapa mental, tem caráter de representação do espaço, segundo a "cartografia fenomenológica", preocupada em representar sentidos e significados da espacialidade vivida. Na revisão bibliográfica feita sobre ele (DE PAULA, 2010 e SANTOS, 2011) não foi encontrado categoria de análise deste. Assim sendo, propomos uma primeira leitura deste desenho cartográfico, com base em categorias identificadas a partir de estudos da Geografia, conforme o Quadro 1, abaixo.

Quadro 1 - Critérios de análise

\begin{tabular}{|c|c|c|c|}
\hline \multirow{7}{*}{ 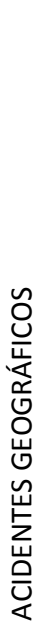 } & \multirow[t]{2}{*}{ NATURAIS } & \multicolumn{2}{|c|}{ rio, baía, oceano, morro, serra, ladeira, plano inclinado. } \\
\hline & & EDIFICAÇÕES & $\begin{array}{l}\text { ponte, cais, avenida, prédio, viaduto, cemité- } \\
\text { rio, rua e casa. }\end{array}$ \\
\hline & \multirow{5}{*}{ ARTIFICIAIS } & $\begin{array}{l}\text { ESPAÇOS } \\
\text { COMERCIAIS E } \\
\text { EDUCACIONAIS }\end{array}$ & posto de gasolina, escola, padaria. \\
\hline & & ESPAÇOS DE LAZER & pizzaria, praça, hotel, academia \\
\hline & & VEÍCULOS & $\begin{array}{l}\text { carros de passeio, caminhões, transporte } \\
\text { coletivo. }\end{array}$ \\
\hline & & BAIRROS & localidade no entorno do centro. \\
\hline & & PROPAGANDA & letreiros, outdoor, luminosos, placas \\
\hline
\end{tabular}


Tabela 1 - Categoria de análise por desenho

\begin{tabular}{|c|c|c|c|c|c|c|}
\hline \multicolumn{3}{|c|}{ SÉRIE E TURMA } & $10 \mathrm{~A}$ & $10 \mathrm{~B}$ & $10 \mathrm{C}$ & $10 \mathrm{D}$ \\
\hline \multirow{7}{*}{  } & \multicolumn{2}{|l|}{ NATURAIS } & 2 & - & 2 & 1 \\
\hline & \multirow{6}{*}{ ARTIFICIAIS } & EDIFICAÇÕES & 4 & 16 & 14 & 6 \\
\hline & & $\begin{array}{l}\text { ESPAÇOS COMERCIAIS E } \\
\text { EDUCACIONAIS }\end{array}$ & 3 & 1 & 1 & 1 \\
\hline & & ESPAÇOS DE LAZER & 4 & 1 & 3 & 1 \\
\hline & & VEÍCULOS & 1 & - & - & - \\
\hline & & BAIRROS & - & - & 2 & 1 \\
\hline & & PROPAGANDA & 1 & - & - & - \\
\hline \multicolumn{3}{|c|}{ TOTAL } & 15 & 18 & 22 & 10 \\
\hline
\end{tabular}

Esta análise parte do princípio da observação dos locais representados nos mapas mentais, possibilitando-nos ver o que é mais significante para cada aluno, uma vez que estes mapas retratam o percurso realizado por ele, de sua casa à escola. Neles foram inseridos dois símbolos, a fim de orientar a leitura dos mesmos, utilizando o círculo $(Q)$ para representar a casa do aluno e o triângulo $(\Delta)$, a escola.

Os quatro mapas mentais referenciados retratam, predominantemente, o espaço urbano entre a casa e a escola desses sujeitos. Ao analisar cada um deles a partir dos critérios apresentados no Quadro 1, podemos chegar às frequências de características indicadas na Tabela 1, sendo dentre os acidentes geográficos artificiais, as edificações, as mais citadas.

Outra observação importante é que em todos os mapas, quando os alunos se deparam com as limitações em representar determinados lugares de sua vivência através do desenho, eles recorrem ao uso das palavras, como mecanismo de identificação.

Também é percebido reduzida referência em relação aos elementos naturais, fato que demonstra, claramente, o olhar dos alunos quando realizam o desenho do percurso de sua cara à escola, caracterizando, amplamente, a percepção do espaço urbano. 
Figura 1 - "M. de N. M (1ㅇano A)"

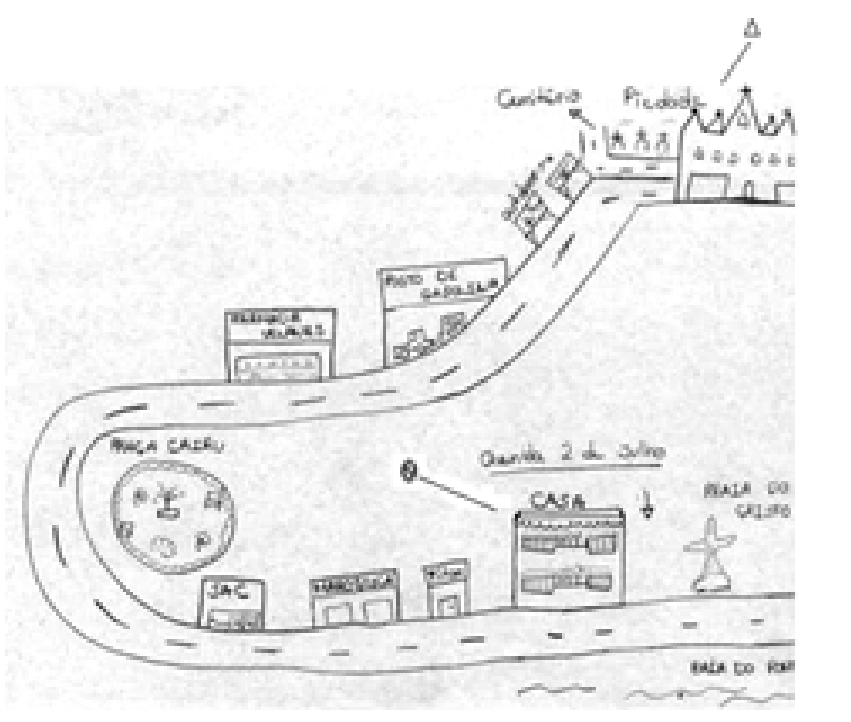

Fonte: Acervo pessoal do aluno

Figura 2 - "J. F. S. F. (1 ano B)"

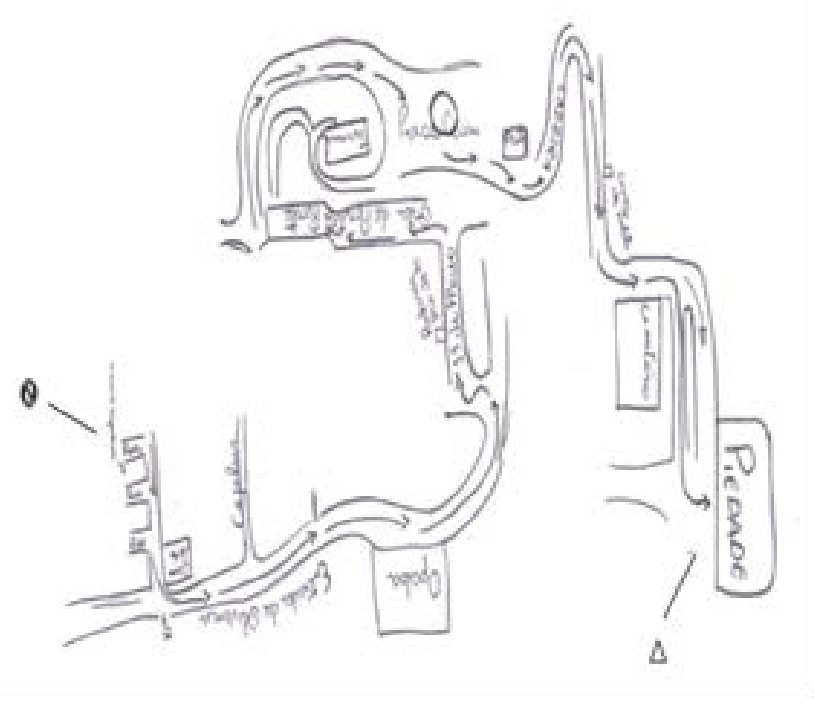

Fonte: Acervo pessoal do aluno 
Figura 3 - "G. G. de L. (1ํa ano C)"

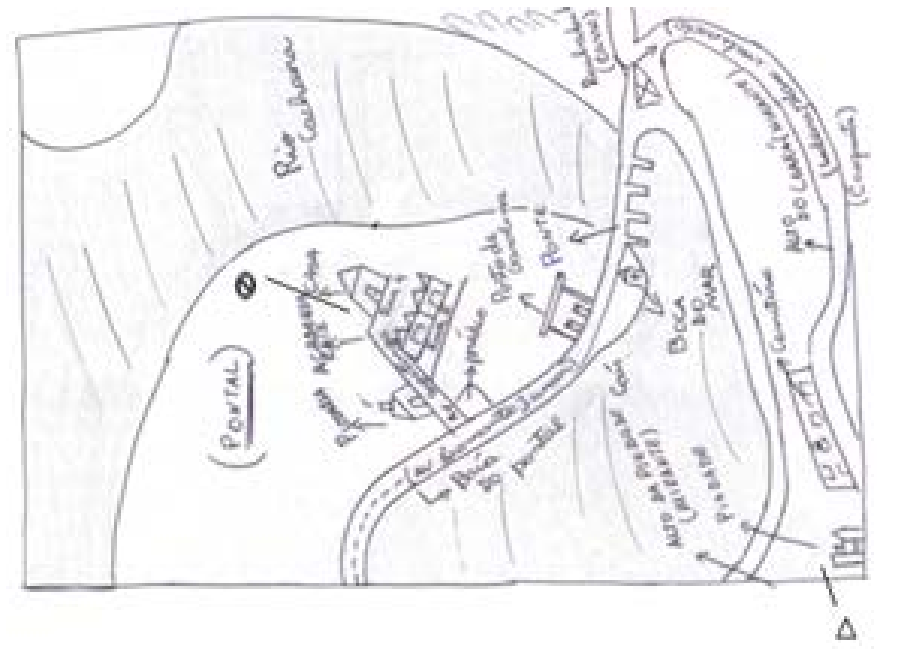

Fonte: Acervo pessoal do aluno

Figura 4 - “G .S. D. G.(1ㅇa ano D)”

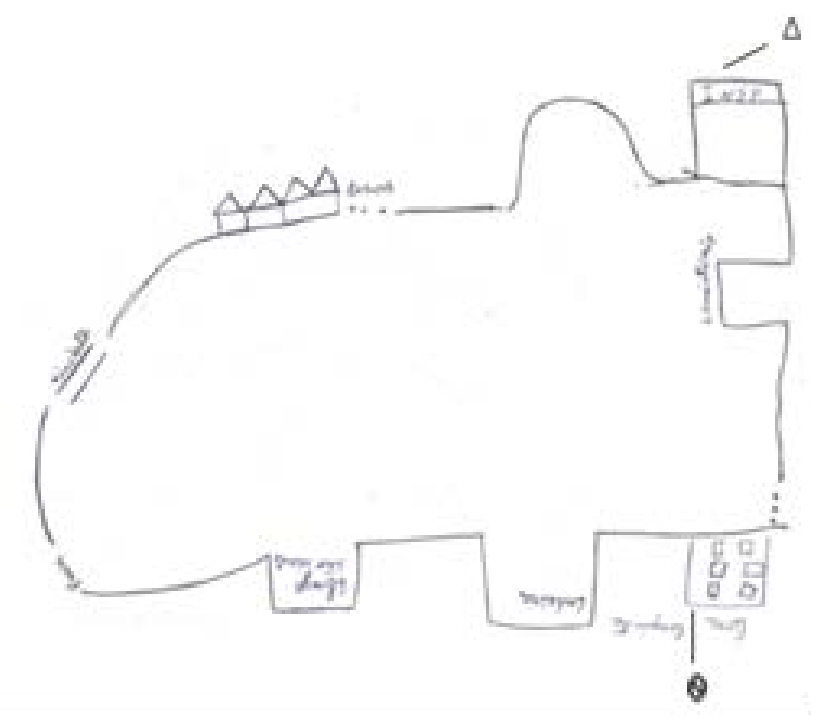

Fonte: Acervo pessoal do aluno

102 Número temático: Desenho e Educação: Cultura Visual e Cidade. A Cor das Letras - UEFS, $n$.

13, 2012 
Quanto ao mapa mental da aluna do 10 ano A (Figura 1), pode-se observar que embora a mesma não tenha apresentado o maior número de categorias, sua percepção quanto ao espaço vivido e percorrido aparentemente foi a que apresentou um maior número de detalhes, deixando apenas uma categoria sem referenciar, quando os demais deixaram duas ou mais. Realizou o desenho demonstrando a praça enquanto contorno, tracejando o percurso realizado, pontuando os espaços de propaganda e inclusive destacando o carro associado ao posto de gasolina. A presteza do delineamento das linhas, os contornos das bordas e flores constatam, de certa forma o detalhismo da natureza feminina. Neste mapa está configurada a relação de afetividade com o vivido e como afirma Chiapetti (2009, p. 93):

A conexão entre os sentimentos e o processo cognitivo propicia à pessoa uma vida de grande sensibilidade, que pode ser cada vez mais apreciada, na medida em que cada um desenvolve a sua capacidade afetiva e suas potencialidades diferenciais.

O autor do mapa mental do 10 ano B (Figura 2) trabalha os contornos de forma bastante delineados, bem distribuída em termo de espaço e deixa bem claro as bifurcações complexas do trânsito. Contudo se dedicou em representar de forma mais contundente a categoria de edificações, já que das 18 referências classificadas, 16 pertencem a ela, restando apenas uma para espaços comerciais e educacionais e outra para espaço de lazer.

É importante ressaltar que o percurso que ele faz é de aproximadamente $70 \%$ de orla marítima, onde está localizado um grande número de espaços de lazer, no entanto não há muitas referências deles em seu mapa mental.

Já o autor do 1 ㅇaㅅ ano C (Figura 3), demonstra uma elevada percepção do lugar em que vive, destacando o maior número de categorias. Das 22 referências (conforme a Tabela 1), o que está mais citado são as edificações, totalizando 14 referências. Porém, deve ser ressaltada a forma como ele utiliza o espaço da folha de oficio, pois a cidade é visivelmente apresentada no centro, rodeada pelo Rio Cachoeira e a Baía do Pontal. Fenômeno que deixa bem claro a noção que o mesmo possui da espacialidade territorial da Cidade de Ilhéus, destacando as questões físicas e naturais do percurso, estabelecendo os limites existentes entre o natural e o artificial.

Este autor demonstra ainda a percepção que detém em relação à "roubadinha", local no qual os carros realizam constantemente contra mão, evitando percorrer maiores distâncias e, que se encontra justamente na confluência da Ponte do Pontal e a referida entrada da rua onde está locali- 
zada a escola. Percebe-se também que a casa dele está localizada em um lugar de intensa socialização, pois os ambientes de lazer circundam sua residência.

Em se tratando do mapa mental do aluno do 10 ano D (Figura 4), é pertinente observar como o desenho realizado por ele apresenta um reduzido número de símbolos, uma vez que representa apenas 10 itens (o menor entre os mapas analisados). Ele utiliza uma única linha para traçar o percurso, sem necessariamente apresentar a direção do caminho percorrido e pelo fato de trazer poucos acidentes geográficos artificiais, exceto as edificações, é possível supor haver uma dificuldade de socialização com o espaço vivido, especificado a partir dos poucas categorias significativas para ele. Pois como afirma De Paula $(2010$, p. 3) "a maneira como pessoas percebem o ambiente pode revelar as decisões e condutas que elas têm sobre esse meio."

\section{CONCLUSÃO}

Registrar a percepção do aluno se faz necessário à medida que se observa as limitações existentes quanto ao desenho da cartografia e caracteriza a necessidade de estimular esta prática nas escolas, uma vez que os professores da disciplina de Geografia se deparam sempre com a mesma angústia: como ensinar mapas para os alunos e levá-los a perceberem a importância que estes possuem enquanto representação e leitura.

Uma vez que o aluno se debruça sobre o papel e registra em forma de desenho sua realidade percebida é notória a presença da Geografia Humanista, pois ali se encontra suas sensações, frustrações, interagindo com o mundo e percebendo como pertencente a ele. Não se trata de alguém que olha de longe seu objeto de estudo, aferindo de forma pragmática e positivista os resultados encontrados.

Além desta atividade, estimular a compreensão do espaço social e vivido pelo sujeito, também pode ser utilizada pela coordenação para identificar as distâncias percorridas pelos alunos e a partir dos dados coletados, compreendendo comportamentos referentes à pontualidade e/ou atrasos com relação ao primeiro horário de aula, bem como universo cognitivo e de socialização dos mesmos.

Por fim, promover uma maior discussão sobre os mapas mentais, colabora tanto para a construção de novos saberes dos professores de Geografia, bem como na otimização do ensino aprendizagem, realizados em 
sala de aula, visto que o conhecimento só tem sentido quando consegue provocar transformações.

\section{REFERÊNCIAS}

AUSUBEL, D. P; NOVAK, J. D.; HANESIAN, H. Psicologia educacional. Rio de Janeiro: Ed. Interamericana, 1980.

CAMARGO, Luis Henrique Ramos de; GUERRA, Antonio José Teixeira. A geografia da complexidade: aplicação das teorias da auto-organização ao espaço geográfico. Contribuições à historia e à epistemologia da geografia. Riode Janeiro: Bertrand Brasil, 2007

CARVALHO, M. S. O pensamento geográfico medieval e renascentista no ciberspace. In: Rosely Sampaio Archela; Tania Maria Fresca; Rosana Figueiredo Salvi. (Org.). Novas tecnologias. Londrina: EDUEL, 2001, v. 1, p. 101-113.

CHIAPETTI, Rita Jaqueline Nogueira. Na beleza do lugar, o Rio das Contas indo... ao mar. Tese de doutorado na área de organização do espaço. Rio Claro, 2009.

CLAVAL, Paul. A revolução pós-funcionalista e as concepções atuais da geografia. In: MENDONÇA, Francisco, KOZEL, Salete. Elementos de epistemologia da geografia contemporânea. Curitiba: UFPR, 2002.

COSTA, Fabio Rodrigues da; ROCHA, Marcio Mendes. Geografia: conceitos e paradigmas apontamentos preliminares. Revista GEOMAE - Geografia, Meio Ambiente e Ensino, v. 1, n. 2, 2. sem. 2010.

DE PAULA, Luiz T. Mapas mentais e experiência: um olhar sobre as possibilidades. In: Anais do XVI Encontro Nacional de Geógrafos. Porto Alegre, 2010.

FERREIRA, Edson Dias. Desenho e antropologia: influências da cultura na produção autoral. In: Anais do VI International Conference on Graphics Engineering for Arts and Design. Recife, 2005.

GOMES, Luiz Vidal Negreiros. Desenhismo. 2. ed. Santa Maria: Ed. UFSM, 1996.

MOREIRA, Marco Antonio. Mapas conceituais e aprendizagem significativa O Ensino, Revista Galáico-Portuguesa de Sócio-Pedagogia e Sócio-Linguística. Pontevedra/Galícia/Espanha e Braga/Portugal, n. 23 a 28, p. 87-95, 1988.

OLIVEIRA, Livia de. Ainda sobre a percepção e representação em geografia. In: MENDONÇA, Francisco, KOZEL, Salete. Elementos de epistemologia da geografia contemporânea. Curitiba: UFPR, 2002.

OLIVEIRA, Livia de. Estudo metodológico e cognitivo do mapa. São Paulo: USP-IGEOG, 1978.

PAIVA, Eduardo França. A iconografia na história. História \& imagem. Belo Horizonte: Autêntica, 2006.

ROCHA, Lurdes Bertol. Fenomenologia, semiótica e geografia da percepção: alternativa para analisar o espaço geográfico. Revista da Casa da Geografia de Sobral, Sobral, v. 4/5, p. 67-79, 2002/2003.

SANTOS, L. L. Mapa mental e lugar: a percepção dos moradores das Vilas Rurais Recanto Verde e Nova Jerusalém. Caminhos de Geografia (UFU), v. 12, p. 231-242, 2011. 
SANTOS, Milton. A natureza do espaço: técnica e tempo, razão e emoção. 4. ed. São Paulo: Ed. USP, 2004.

SOUZA, Nadia Aparecida de; BORUCHOVITCH, Evely. Mapas conceituais e avaliação formativa: tecendo aproximações. Educação e Pesquisa. São Paulo, v. 36, set./dez. 2010.

TRINCHÃO, Glaucia M. C.; OLIVEIRA, Lysie dos Reis. A história contada a partir do desenho. In: Graphica 98: II Congresso Internacional de Engenharia Graphica nas Artes e no Desenho e XIII Simpósio Nacional de Geometria Descritiva e Desenho Técnico. Feira de Santana: UEFS, 1998. 